\title{
ANALISIS BIAYA PRODUKSI DAN PENDAPATAN PETANI PADA USAHATANI BIBIT JERUK KALAMANSI DI KABUPATEN BENGKULU TENGAH PROVINSI BENGKULU
}

\section{THE INCOME ANALYSIS BUSINESS FARMER CITRUS KALAMANSI IN BENGKULU CENTRAL}

Evi Andriani, Aleksandser

Program Studi Agribisnis Fakultas Pertanian, Universitas Dehasen Bengkulu

\begin{abstract}
ABSTRAK
Penelitian ini bertujuan mengetahui tingkat pendapatan usaha tani bibit jeruk kalamansi di Balai Benih Induk Hortikultura (BBIH) Bengkulu Tengah. Penelitian dilaksanakan pada bulan Agustus tahun 2015. Metode pengumpulan data penelitian terdiri dari data primer dan data sekunder. Data primer untuk analisis usaha tani diperoleh dengan melakukan wawancara langsung dengan petani (responden) binaan Balai Benih Induk Hortikultura (BBIH) Bengkulu Tengah dibantu dengan panduan daftar pertanyaan dalam bentuk kuisioner. Data sekunder diperoleh dari Balai Benih Induk Hortikultura (BBIH) Bengkulu Tengah. Badan Pusat Statistik (BPS), Dinas Pertanian Bengkulu Tengah, Dinas Pertanian Propinsi Bengkulu, penelitian sebelumnya dan literatur lainnya data yang diperoleh di analisis dengan analisis usaha tani. Dari penelitian ini dihasilkan Total pendapatan rata-rata usaha tani penangkar benih bibit jeruk kalamansi di Balai benih induk Hortikultura (BBIH) Bengkulu Tengah, pertahun adalah sebesar Rp. 20,704,289,- pertahun. Pendapatan tersebut diperoleh dari dari total rata- rata penerimaan (TR) Rp. 59,369,789 dikurangi total biaya (TC) Rp. 38.665.500
\end{abstract}

Kata kunci : Jeruk Kalamansi, usaha tani, Balai Benih Induk Holtikultura

\section{ABSTRACT}

This study aims to know the level of farm income Kalamansi citrus seedlings in seed parent Horticultural Hall (BBIH) Bengkulu middle. Data collection methods consisted of primary data and secondary data. Primary data for the analysis of farm obtained by direct interviews with farmers (respondents) Hall built Horticulture Seeds (BBIH) Central Bengkulu assisted by guide lists the questions in the questionnaire form. Income levels farm produced seed Kalamansi citrus seedlings in seed parent Horticultural Hall (BBIH) Bengkulu is the middle year of Rp. 20,704,289, - per year Total revenue (TR) $R p$ 59,369,789 minus Total Cost (TC) Rp. 38,665,500

Keywords : jeruk kalamansi; farming ; BBIH

\section{PENDAHULUAN}

Dalam menyelenggarakan usahatani, setiap petani berusaha agar hasil panennya banyak (produksi tinggi) dan kemudian dapat dijual dengan harga yang tinggi sehingga dapat mensejahterakan petani. Bagi seorang petani analisis pendapatan memberikan bantuan untuk mengukur 
apakah kegiatan usahanya pada saat ini berhasil atau tidak (Supriyanto et al., 2006). Pendapatan usahatani akan berbeda untuk setiap petani, dimana perbedaan ini disebabkan oleh perbedaan faktor produksi, tingkat produksi yang dihasilkan dan harga jual yang tidak sama hasilnya (Ridwan et al.,2008, Nurdin, 2005).

Prinsip penting yang perlu diketahui dalam menganalisis mengenai pendapatan usahatani adalah keterangan mengenai keadaan penerimaan dan keadaan pengeluaran. Dalam analisis ini akan dikaji seberapa jauh setiap nilai rupiah biaya yang digunakan dalam kegiatan usahataninya dapat memberikan sejumlah nilai penerimaan sebagai manfaatnya (Soekartawi et al., 1986).

Salah satu komoditas pertanian yang menjadi perhatian pemerintah Provinsi Bengkulu adalah komoditas jeruk kalamansi (Citrus microcarpa). Manfaat jeruk ini sangat banyak selain untuk memasak ikan, sambal dan untuk sari buah minuman segar jeruk ini sangat kaya akan mineral dan vitamin $\mathrm{C}$. Oleh karena itu sangat baik digunakan untuk minuman buah bernutrisi. Kandungan mineral dan vitamin $\mathrm{C}$ itu sangat baik untuk mencegah penyakit pernafasan, penguat tulang dan pemacu pertumbuhan. Setiap rumah tangga sebaiknya menggunakan jeruk ini untuk obat, bumbu dapur, bumbu kue, ramuan cantikan dan minuman segar
(Rukmana, 2003). Jeruk kalamansi ini merupankan jenis tanaman semak, kayunya memiliki banyak cabang-cabang kecil dan berdaun rimbun (Sunarjono, 2000).

Jeruk kalamansi ini sebenarnya sudah cukup banyak dibeberapa daerah di Indonesia, tetapi dengan nama yang beragam (Tjakrawiralaksana dan Soeriaatmadja, 1983). Di Propinsi Bengkulu jeruk kalamansi sudah dibudidayakan di Balai Benih Induk Hortikultura (BBIH) Bengkulu Tengah telah dilakukan penangkaran bibit dengan sistem cangkok, sambung, stek atau pucuk atau okulasi. Tujuan penelitian ini adalah untuk melakukan analisis pendapatan pada usaha tani jeruk kalamansi di Balai Benih Induk Hortikultura (BBIH) Bengkulu Tengah.

\section{METODE PENELITIAN}

\section{Tempat dan Waktu Penelitian}

Penelitian ini dilaksanakan di Desa Talang Aling, Kecamatan Talang Empat, Kabupaten Bengkulu Tengah, Propinsi Bengkulu, dan Balai Benih Induk Hurtikultura (BBIH) Bengkulu Tengah pada bulan agustus tahun 2015. Pemilihan lokasi penelitian dilakukan dengan sengaja (purposive) dengan pertimbangan bahwa Kabupaten Bengkulu Tengah merupakan salah satu penghasil jeruk kalamansi di Propinsi Bengkulu. 


\section{Metode Pengumpulan Data}

Pengumpulan data penelitian terdiri dari data primer dan data sekunder. Data primer untuk analisis usaha tani diperoleh dengan melakukan wawancara langsung dengan petani (responden) binaan Balai Benih Induk Hortikultura (BBIH) Bengkulu Tengah dibantu dengan panduan daftar pertanyaan dalam bentuk kuisioner. Data sekunder diperoleh dari Balai Benih Induk Hortikultura (BBIH) Bengkulu Tengah, Badan Pusat Statistik (BPS), Dinas Pertanian Bengkulu Tengah, Dinas Pertanian Propinsi Bengkulu dan penelitian sebelumnya.

\section{Metode Penarikan Contoh}

Pengambilan responden untuk petani dipilih secara sengaja (purposive sampling), karena jumlah petani yang sangat terbatas. Adapun petani yang dipilih adalah petani yang memproduksi jeruk kalamansi binaan Balai Benih Induk Hortikultura (BBIH) Bengkulu Tengah yaitu sebanyak 35 orang responden

\section{Metode Pengolahan dan Analisis Data}

Data yang digunakan adalah data kuantitatif dan kualitatif. Data kuantitatif diolah dengan menggunakan analisis pendapatan usaha tani. Data kualitatif dianalisis secara deskriptif yaitu analisis pendapatan usaha tani dari komoditi jeruk kalamsi

\section{a. Analisis Pendapatan Usahatani}

Pendapatan dalam penelitian ini akan dibedakan menjadi dua, pertama pendapatan atas biaya tunai (pendapatan tunai) yaitu biaya yang benar- benar dikeluarkan secara tunai oleh petani (explicit cost). Kedua, pendapatan atas biaya total (pendapatan total) dimana semua input milik keluarga juga diperhitungkan sebagai biaya. Secara umum pendapatan diperhitungkan sebagai penerimaan dikurangi dengan semua biaya yang telah dikeluarkan, baik biaya tunai maupun tidak tunai (Soekartawi et al.,1986). Secara matematis tingkat pendapatan usaha tani sebagai berikut:

$$
\begin{array}{ll}
\text { I tunai }= & \mathrm{NP}-\mathrm{BT} \\
\text { I total }= & \mathrm{NP}-(\mathrm{BT}+\mathrm{BD}) \\
\text { Keterangan : } \\
\text { I tunai : } & \text { Pendapatan Tunai } \\
\text { I toatal : } & \text { Pendapatan Total } \\
\mathrm{NP} \quad: & \text { Nilai Produksi (jumlah } \\
& \text { produk x harga output) (Rp) } \\
\mathrm{BT} \quad: & \text { Biaya Tunai (produksi, } \\
& \text { tenaga kerja luar keluarga, } \\
& \text { dan pajak lahan) (Rp) } \\
\mathrm{BD} & \text { Biaya Diperhitungkan (sewa } \\
& \text { lahan, penyusutan alat, dan } \\
& \text { tenaga kerja dalam keluarga, } \\
& \text { serta biaya bibit sendiri) } \\
& \text { (Rp) }
\end{array}
$$

Biaya penyusutan alat- alat pertanian diperhitungkan dengan membagi selisih 
antara nilai pembelian dengan nilai sisa yang ditafsirkan dengan lamanya modal pakai. Metode yang digunakan ini adalah metode garis lurus. Metode ini digunakan karena jumlah penyusutan alat tiap tahunnya dianggap sama dan diasumsikan tidak laku bila dijual (Soekartawi et al., 1986).

\section{b. Analisis Perbandingan Penerimaan dan Biaya (R/C-ratio)}

Analisis pendapatan usahatani selalu disertai dengan pengukuran efisiensi.Untuk mengukur efisiensi masing- masing usahatani terhadap setiap penggunaan satu satuan unit yang memberikan kelipatan atau ratio antara jumlah penerimaan dengan jumlah biaya yang merupakan perbandingan antara penerimaan kotor yang diterima usahatani dari setiap mata uang yang dikeluarkan dalam proses produksi. Perhitungan R/C ratio dapat dirumuskan sebagai berikut (Soekartawi et al., 1986) :

Ratio $\mathrm{R} / \mathrm{C}$ atas biaya tunai $(\mathrm{TI})=$ Total Penerimaan (TR) -Total Biaya Tunai (TC) Jika nilai $\mathrm{R} / \mathrm{C}>1$, maka penerimaan yang diperoleh lebih besar dari tiap unit biaya yang dikeluarkan untuk memperoleh penerimaan tersebut dan usaha tersebut menguntungkan. Jika R/C $<1$, berarti penerimaan yang diterima lebih kecil dari tiap unit yang dikeluarkan, maka usahatani tersebut tidak menguntungkan untuk dijalankan.

\section{HASIL DAN PEMBAHASAN}

Profil Balai Benih Induk Hortikultura (BBIH) Bengkulu Tengah

Lokasi BBI Hortikultura terletak di Dusun Talang Aling Desa Taba Lagan Kecamatan Talang Empat Kabupaten Bengkulu Tengah berjarak $20 \mathrm{KM}$ dari Ibukota Provinsi Bengkulu, mempunyai luas lahan 45,5 Ha. Sudah dikelola dengan baik seluas $23 \mathrm{Ha}$, dan sisanya seluas 22 merupakan lahan yang belum dimanfaatkan secara optimal. Secara umum mempunyai jenis tanah Podsolik Merah Kuning (PMK) / Ultisol dengan PH tanah 5-6 dengan ketinggian tempat 60 meter dari permukaan laut. Luas Lahan Balai Benih Induk Hortikultura Talang Aling dan Pemanfaatannya disajikan pada Tabel 1. 
Tabel 1. Luas Lahan BBIH Talang Aling dan Pemanfaatannya

\begin{tabular}{|c|c|c|}
\hline No & Pemanfaatan Lahan & Luas ( Ha ) \\
\hline & Bangunan & 1 \\
\hline . & Pembibitan & 1 \\
\hline & Tanaman Buah-buahan (Pohon Induk dan Koleksi) & 10 \\
\hline & Tanaman Sayuran & 1 \\
\hline & Tanaman Hias & 0,5 \\
\hline & Tanaman Obat / Aneka Tanaman & 1 \\
\hline & Diusahakan Untuk Padi Sawah dan Kolam & 3 \\
\hline & Pengembangan Tanaman Buah-buahan & 6 \\
\hline & Belum Diusahakan Untuk Komoditas & 22 \\
\hline & J U M L A H & 45,5 \\
\hline
\end{tabular}

Sumber : LAPTAH BBIH Bengkulu Tengah (2014)

Adapun topografi lahan BBI Hortikultura

Talang Aling adalah bergelombang dengan sebagian kecil 5 Ha rawa yang dapat dimanfaatkan untuk usaha padi sawah dan perikanan darat, sedangkan temperatur rata-rata adalah $25^{\circ} \mathrm{C}-29^{\circ} \mathrm{C}$ dengan rata-rata curah hujan $3.388 \mathrm{~mm}$ pertahun dan hari hujan 144 hari Pertahun

\section{Tugas dan Fungsi BBI Hortikultura}

Sesuai dengan Peraturan Daerah Provinsi Bengkulu Nomor 7 Tahun 2008, maka Kepala Balai berada dibawah dan bertanggung jawab kepada Kepala Dinas Pertanian Provinsi Bengkulu serta berkedudukan sebagai pelaksana teknis operasional Dinas dengan tugas melaksanakan sebagian kewenangan desentralisasi dan dekonsentrasi Dinas Pertanian dibidang penyediaan benih/bibit hortikultura bermutu dari varietas/klon unggul bagi masyarakat sesuai dengan prinsip 7 tepat (jenis, mutu, varietas, jumlah, lokasi, waktu dan harga). Berarti Balai tersebut mempunyai peran dalam pemasaran buah jeruk (Sudana et al., 2007).

\section{Profil Responden di BBIH \\ Profil Umur}

Rata-rata umur penangkar benih jeruk okulasi adalah 44,3 tahun dengan kisaran 30 sampai 50 tahun. Tingkat pendidikan rata-rata SLTA sanpai sarjana pengalaman kerja dengan rata-rata 7,5 tahun. Persentase umur penangkar benih jeruk okulasi terbanyak pada rentang usia 40-48 tahun yaitu sebanyak 20 orang atau $57,14 \%$ hal ini dapat menunjukan bahwa semakin tingi usia tidak mempengaruhi masa produktif untuk menghasilkan, dimana pada usia 40-48 tahun keluarga responden mulai memenuhi kebutuhan hidup yang tinggi seperti anak memasuki jenjang kuliah (Tabel 2). 
Tabel 2. Profil Umur Penangkar Benih Jeruk Okulasi di BBIH

\begin{tabular}{llllll}
\hline No & \multicolumn{1}{c}{ Umur (Tahun) } & & Jumlah Responden & & Persentase (\%) \\
\hline 1 & $>25$ & - & & - & \\
2 & $25-39$ & 6 & & 17,14 & \\
3 & $40-48$ & 20 & 57,14 & \\
4 & $49-55$ & 9 & 25,72 & \\
\hline
\end{tabular}

Sumber : Pengolahan Data Primer (2015)

Tabel 3. Profil Tingkat Pendidikan Penangkar Benih Jeruk Okulasi di BBIH

\begin{tabular}{lclc}
\hline No & Tingkat Pendidikan & Jumlah Responden & Persentase (\%) \\
\hline 1 & SMP & 9 & 25,72 \\
2 & SLTA & 25 & 71,42 \\
3 & Sarjana & 1 & 2,86
\end{tabular}

Sumber : Pengolahan Data Primer (2015)

Tabel 4. Profil Pengalaman Penangkar Benih Jeruk Okulasi di BBIH

\begin{tabular}{lccl}
\hline No & Pengalaman (Tahun) & Jumlah Responden & Persentase (\%) \\
\hline 1 & $1-3$ & 10 & - \\
2 & $4-6$ & 25 & 28,57 \\
3 & $7-10$ & & 71,57
\end{tabular}

Sumber : Pengolahan Data Primer (2015)

\section{Profil Tingkat Pendidikan}

Pendidikan merupakan faktor yang ikut menentukan keberhasilan penangkar benih jeruk okulasi, pendidikan dianggap salah satu sarana untuk menunjukan dan membangun masyarakat. Tingkat pendidikan penangkar benih jeruk okulasi dalam peneliatian ini adalah rata-rata tamatan SLTA Tabel diatas menunjukan penangkar benih jeruk okulasi tamat sltp 9 orang $(25,72 \%)$, tamat SLTA 25 orang $(71,42 \%)$ dan tamat sarjana 1 orang $(2,86 \%)$. Hal ini menunjukan bahwa dengan tingkat pendidikan rata-rata SLTA dapat mempengaruhi kualitas pekerjaan seperti mampu bekerja secara kelompok (Tabel 3).

\section{Profil Pengalaman}

Tabel diatas dapat dilihat bahwa sebanyak 25 orang atau sebesar $71,43 \%$ penangkar benih jeruk okulasi telah menekuni usaha 7-10 tahun dan 10 orang atau 28,57\% penangkar benih jeruk okulasi menjalankan usaha selama 4-6 tahun. Dari data dapat dilihat responden dengan pengalaman 10 tahun menghasilkan persentase pendapatan yang tinggi dibandingkan dengan pengalaman dibawah 10 tahun (Tabel 4). 
Analisis Usaha Tani Bibit Jeruk Kalamansi

Usahatani adalah satuan organisasi produksi dilapangan pertanian dimana terdapat unsur lahan yang mewakili alam, unsur tenaga kerja yang bertumpu pada anggota keluarga tani, unsur modal yang beraneka ragam jenisnya, dan unsur pengelolaan dan manajemen yang perannya dibawakan seseorang yang disebut petani (Tjakrawalaksana dan Soriaatmaja, 1983). Makeham dan Malcolm (1991) mendefinisikan usahatani sebagai cara bagaimana mengelola kegiatan -kegiatan pertanian dengan petani sebagai pengelolanya. Jadi analisis usaha tani bibit jeruk kalamansi di Balai Benih Induk Hortikultura (BBIH) Bengkulu Tengah adalah cara bagaimana mengelola kegiatan-kegiatan pertanian terdiri dari unsur lahan yang mewakili alam, unsur tenaga kerja dan unsur modal untuk pengelolaan bibit jeruk kalamansi di Balai Benih Induk Hortikultura (BBIH) Bengkulu Tengah

\section{Analisis pendapatan}

Pendapatan adalah selisih antara penerimaan (TR) dengan total biaya (TC). Penerimaan didapat dari hasil perkalian antara berapa besar produksi yang dicapai dan dapat dijual dengan harga satuan komoditi tersebut di pasar. Pengeluaran usahatani dapat diperoleh dari perolehan nilai penggunaan faktor produksi serta seberapa besar penggunaanya pada suatu proses produksi yang bersangkutan (Soekartawi et al., 1986). Besarnya pendapatan ditentukan oleh besar kecilnya volume produksi yang dihasilkan dan biaya-biaya yang dikeluarkan (Ferdiansyah, 2004). Dengan jumlah rata - rata penerimaan $\mathrm{Rp} 59,369,789$ per tahun dan toyal biaya $\operatorname{Rp} 38,665,500$ maka jumlah pendapatan rata - rata nya adalah TR - TC sebesar Rp 20,704,289.

Penerimaan total $(\mathrm{TR})=2,077,942,614$ Toral biaya $(\mathrm{TC})(\mathrm{Rp}) \quad=1,353,292,493$

Pendapatan Rata Rata

$=(\mathrm{TR}$ rata-rata $)-(\mathrm{TC}$ rata - rata $)$

$=$ Rp. 59,369,789-Rp. $38,665,500$

$=$ Rp. $20,704,289$

\section{Penerimaan (TR)}

Menurut Soekartawi $d k k \quad$ (1986), penerimaan usahatani adalah nilai produk total usahatani dalam jangka waktu tertentu. Penerimaan cabang usaha adalah jumlah salah satu produk usahatani dalam jangka waktu tertentu. Penerimaan ini mencakup produk yang dijual, dikonsumsi rumah tangga petani, digunakan dalam usahatani untuk bibit, digunakan pembayaran, dan yang disimpan. Penerimaan ini dinilai berdasarkan perkalian antara total produksi dengan harga pasar yang berlaku. 
Penerimaan rata-rata penangkar benih jeruk okulasi adalah Rp 59,369,789 per tahun dengan produksi rata-rata 8,824 batang per tahun. Dari data dapat dilihat bahwa penerimaan dengan persentase keseluruhan yang tinggi yaitu $50 \%$ terdapat pada persentase daya kecambah 77\% jumlah tegakan765 dan jumlah okulasi $86 \%$. Hal ini dapat tercapai karena responden melakukan pemeliharaan yang intensif dan mempunyai tenaga kerja okulator yang ahli. Penerimaan dari bibit yang tersalurkan 244.463 batang,dengan harga jual bibit Rp. 8.500 (Tabel 6).

Jumlah Produksi $(\mathrm{RP})=244.463 .837$

Penerimaan rata- rata $(\mathrm{Rp})$

$=$ Produksi rata-rata X Harga Jual

$=(8.824) \times(., 500)$

$=59.369 .789$

\section{a. Biaya Penyusutan Alat}

Alat-alat yang digunakan dalam kegiatan penangkaran benih jeruk okulasi ini tidak habis dipakai dalam satu kali penangkaran. Biaya penyusutan peralatan yang dihitung adalah semua peralatan yang dipakai oleh penangkar benih jeruk okulasi dalam melakukan penangkaran. Peralatan yang di gunakan dalam penangkar benih jeruk okulasi meliputi: mesin air, selang, cangkul, arit, gergaji. Pisau okulasi, hand sprayer, ember dan lahan. Biaya penyusutan peralatan penangkar benih jeruk okulasi rata-rata $\mathrm{Rp}$ 2.075.998.- (Tabel 5) pertahun dari total biaya yang dikeluarkan, dari data penyusutan peralatan terdapat perbedaan diantara persentase terkecil, hal ini dikarenakan membeli peralatan dengan harga relatif murah. Biaya penyusutan barang disajikan pada Tabel 5 .

\section{b. Biaya Perizinan Dan Sertifikasi (Pelabelan).}

Biaya perizinan yang dikeluarakan oleh penangkar benih jeruk okulasi adalah sebesar Rp 100.000,-per tahun untuk perpanjangan surat izin usaha pembenihan (siup) yang dikeluarkan oleh Dinas Kehutanan dan Perkebuanan Kabupaten Bengkulu Tengah.

\section{Tabel 5. Biaya Penyusutan Barang}

\begin{tabular}{llcc}
\hline No. & Jenis Penyusutan & Jumlah $(\mathrm{Rp})$ & Rata - Rata $(\mathrm{Rp})$ \\
\hline 1. & Selang air & 7.718 .250 & 220.521 \\
2. & Cangkul & 2.143 .333 & 61.238 \\
3. & Air/ Parang & 1.404 .333 & 40.124 \\
4. & Pisau Okulasi & 4.803 .333 & 137.238 \\
5. & Mata tunas & 42.745 .000 & 1.221 .285 \\
6. & Mesin air & 12.506 .000 & 357.314 \\
\hline & Jumlah $(\mathrm{Rp})$ & 72.659 .580 & 2.075 .998 \\
\hline
\end{tabular}


Tabel 6. Pendapatan Petani Jeruk Kalamansi di BBIH

\begin{tabular}{|c|c|c|c|}
\hline \multirow{5}{*}{$\begin{array}{l}\text { No } \\
1\end{array}$} & Jenis & Jumlah Biaya (Rp) & Rata-rata Biaya (Rp) \\
\hline & Biaya Variabel & & \\
\hline & Tenaga Kerja & 844.071 .819 & 24.116 .338 \\
\hline & Bahan bahu & 401.298 .366 & 11.465 .668 \\
\hline & Total Biaya variable (1) & & 35.582 .006 \\
\hline \multirow[t]{5}{*}{2} & Biaya Tetap & & \\
\hline & Penyusutan Alat & 72.659 .917 & 2.075 .998 \\
\hline & Sertipikasi & 35.262 .391 & 1.007 .497 \\
\hline & Total Biaya tetap (2) & & 3.083 .495 \\
\hline & Total Biaya 1dan $2(\mathrm{X})$ & 1.353 .292 .493 & 38.665 .500 \\
\hline \multirow[t]{4}{*}{3} & Penerimaan (Y) & & \\
\hline & Produksi & 244.464 & $8, .24$ \\
\hline & Harga & 297,500 & 8.500 \\
\hline & Total Y & 2.077 .942 .614 & 59.369 .789 \\
\hline 4 & Pendapatan $(\mathrm{Y}-\mathrm{X})$ & 724.650 .121 & 20.704 .89 \\
\hline
\end{tabular}

Biaya setifikasi merupakan biaya yang dikeluar kan untuk membayar pajak daerah dan pembelian label, biaya ini dikeluarkan penangkar benih jeruk okulasi apabila pemohon atau penangkar membuat surat permohonan sertifikasi benih okulasi milik nya sendiri berupa benih siap salur kepada pengawasan dan pengujian mutu benih (BP2MB) dinas perkebunan Perovinsi Bengkulu selaku sertifikator.

BP2MB memeriksa benih jeruk okulasi siap salur milik penangkar dengan cara menghitung populasi, mengamati secara visual dan pengambilan sampel beruoa tolok ukur diameter batang dan tinggi benih. Benih jeruk okulasi yang tidak memenuhi standar teknis diberi tanda berupa cat merah seperti akar bengkok dan terserang hama penyakit, sedangkan benih jeruk okulasi yang kerdil akan dipelihara kembali untuk pengajuan sertifikasi selanjutnya menunggu benih memenuhi standar teknis. Benih yang memenuhi standar teknis akan diberi label biru, dimana setiap benih yang diberi label berupa label biru, akan dikenakan biaya sebesar Rp125,- perbatang, total biaya yang dikeluarkan dalam penangkaran benih jeruk kalamansi okulasi di Balai Benih Induk Hortikultura (BBIH) Talang Aling Bengkulu Tengah adalah jumlah total rata-rata biaya tetap dan biaya variable yaitu sebasar Rp. 38.665.500,per tahun (Tabel 6).

\section{c. Biaya Bahan Baku dan Pelengkap}

Biaya bahan baku berupa biji jeruk diperoleh penangkar benih jeruk okulasi dengan cara membeli secara kelompok di Balai Benih Induk Hortikultura (BBIH) dan dengan harga Rp 200,- perbiji dengan asumsi barang sudah diterimah ditempat. Biaya bahan pelengkap merupakan biaya 
yang dikeluarkan penangkar benih jeruk okulasi untuk membuat jeruk okulasi, bahan pelengkap terdiri dari entres, polibeg, plastic, pupuk, tanah, pestisida, lap pembersih dan bahan bakar. Total biaya bahan baku dan pelengkap yang diperlukan adalah rata-rata sebesar $\mathrm{Rp}$ 11.465.668,- pertahun (Tabel 6).

\section{d. Biaya Tenaga Kerja}

Tenaga kerja dalam pembuatan benih jeruk okulasi di daerah penelitian terdiri dari tenaga staf lapangan Balai Benih Induk Hortikultura. Biaya tenaga kerja dalam penelitian ini rata-rata adalah $\mathrm{Rp}$ 24.116.338,- per tahun (Tabel 6).

\section{KESIMPULAN}

Total pendapatan rata-rata usaha tani penangkar benih bibit jeruk kalamansi di Balai benih induk Hortikultura (BBIH) Bengkulu Tengah, pertahun adalah sebesar Rp. 20,704,289,- pertahun. Pendapatan tersebut diperoleh dari dari total rata- rata penerimaan (TR) Rp. $59,369,789$ dikurangi total biaya (TC) Rp. 38.665 .500

\section{DAFTAR PUSTAKA}

AAK, 1992. Petunjuk praktis bertanam sayuran. Kanisius. Yogyakarta

Ferdiansyah, Herry. 2004. Analisis Pendapatan Usahatani dan Pemasaran Kentang (Kasus di Desa Argamukti Kec. Argapura
Kab. Majalengka, Jawa Barat). Skripsi. Fakultas Pertanian. Institut Pertanian Bogor. Bogor.

Makeham, J. P. dan Malcolm R. L. 1991. Manajemen Usahatani Daerah Tropis. LP3ES. Jakarta.

Nurdin, F. 2005. Penyakit CVPD pada tanaman jeruk serta bio ekologi dan pengendalian vektornya. Jurnal Tambua 4(2) : 134 - 140

Ridwan, H.K, Muharam, Hardiyanto, Ruswandi. 2008. Sifat inovasi dan aplikasi teknologi pengelolaan terpadu kebun jeruk sehat dalam penegembangan agribisnis jeruk. Jurnal Holtikulrura 18(4) : 477490

Rukmana, R. 1994. Tomat dan Cherry. Kanisius, Jakarta.

Soekartawi, 1986. Teori Ekonomi Produksi dengan Pokok Bahasan Analisis Fungsi Cobb-Douglas. Rajawali Press, Jakarta

Soekartawi, A. Soeharjo, John L. Dillon, J. B. Hardaker. 1986. Ilmu Usahatani dan Penelitian Untuk Pengembangan Petani Kecil. UI-Press. Jakarta.

Sudana, W., Moudar, Jamil, Yufdy, Napitupuluh, Daniel, Hayani, Haloho, Darmawan, Suryani. 2007. Karakteristik dan peran kelembagaan pemasaran pada komoditas jeruk. Prosiding seminar nasional inovasi dan alih teknologi spesifik lokasi mendukung revitalisasi pertanian. 770-779

Sunarjono, 2000. Prospek berkebun buah, penebar swadaya, Jakarta

Supriyanto, A., Agisimanto, Purbiati, Devy, Dwiastuti. 2006. Analisis genotipe pohon induk jeruk bebas penyakit hasil perbanyakan tunas pucuk dengan primer RAPD. Jurnal Holtikultura 16 (1) : 1-10

Tjakrawiralaksana, A. dan Soeriaatmadja M. C. 1983. Usahatani. Departemen Pendidikan dan Kebudayaan. Jakarta. 